Este ensaio esboça uma reflexâo acerca do trabalho institucional com crianças psicóticas. Partindo do termo narrativa proposto por $\mathrm{Mi}$ chel de Certeau, que pōe em destaque as "formas de agir" no mundo daqueles que parecem existir à margem dos circuitos oficiais de trocas, a idéia de "bricolage" serve aqui como suporte para uma leitura que pretende apostar na perspectiva de deslocar o olhar e supor que, mesmo sendo aparentemente ininteligível, o esforço incansável dessas crianças no contato com os objetos esboça uma tentativa de construção ainda mais difícil, quando a palavra tem a materialidade do livro, da cadeira, ou da almofada. Psicose; crianças; instituição; grupos; psicanálise

\section{SUBTLE NARRATIVES}

This essay outlines the reflection upon institutional work carried out with psychotic children. Having Michel de Certeau's view of the term narrative - seen as enhancing the "action forms in the world of those who seem to be marginal to the official exchange circuits - as a starting point, the idea of "bricolage" is hereby. used as support to a viewpoint that intends to bet on a perspective that should look elsewhere and suppose that, even if apparently unintelligible, the tireless effort of these children in their contact with the object draws an intent of an even more difficult cons. truction, once the word bears the materiality of a book, a chair or even a cushion.

Psychosis; children; institutional work; groups; psychoanalysis

\section{SUTIS NARRATIVAS}

\author{
Teresinha $\mathrm{N}_{\text {atal }}$ Meirelles
}

\section{"Assim quis o acaso que se falasse uma vez em minha presença de gravuras} [Kupferstich]. No dia seguinte, pus-me debaixo da cadeira e estendia a cabeça para fora; isso era um 'esconderijo de cabeça' [Kopf-verstich]. Se, ao fazer isso, eu me desfigurava e a palavra também, eu só fazia o que devia fazer para criar raízes na vida. Aprendi em tempo a embru-

Ihar-me nas palavras, que eram, de fato, nuvens. $O$ dom de reconhecer semelhanças nada mais é do que um tênue resíduo da antiga coerção a tornar-se semelhante e a comportar-se de maneira semelhante. Essa coerção, as palavras exerciam sobre mim. Não as que me faziam semelhante a modelos de virtude, mas a apartamentos, a móveis, a roupas”

Walter Benjamin'

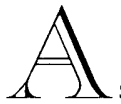

s linhas que se seguem tratarão de alguns aspectos destacados a partir de um trabalho em grupo com crianças psicóticas tomando como artifício o uso de livros. $\mathrm{Na}$ verdade, há um longo caminho a percorrer antes de podermos chegar a esta configuração e tentaremos traçá-lo com a intermediação de alguns aspectos teóricos e situações vividas no decorrer desse trabalho.

Mestre na área de Língua e Literatura Francesa no

Departamento de Letras Modernas da FFLCH-USP, é pesquisadora do Laboratório do Manuscrito Literário dessa mesma faculdade e membro da equipe das Oficinas Terapêuticas da PUC-SP. 
Em 1996 foi criada a oficina de Contar Histórias, como parte do Projeto Oficinas Terapêuticas, iniciado nesse mesmo ano, na Clínica Psicológica Ana Maria Poppovic, da PUC-SP. Inicialmente este projeto era constituído por duas oficinas, Música e Artes, e Movimento; além do acompanhamento dos pais em um grupo semanal. Concebido após um tempo inicial de existência do projeto, o Contar Histórias surgiu num contexto clínico e institucional que the atribuiu o estatuto de trabalhar em um campo mais "formal" da linguagem, uma aposta que aparentemente anunciava um funcionamento mais estruturado e, por vezes, diretivo do trabalho. Esse grupo tinha inicialmente como direção sustentar possibilidades de enredamento das crianças nas tramas que propúnhamos, apostando que nelas se fariam personagens. O termo "oficina", utilizado para todos os grupos desse projeto, foi escolhido como designador da ênfase que pretendíamos pôr no fazer(se) - uma aposta na produção como possibilidade de designar (e portanto situar) o sujeito. $O$ que entendíamos por produção era tornar possível cada um inserir-se nessa rede que se pretendia tecer, não exatamente com uma preocupação ocupacional ou educativa, mas como inveśtimento na possibilidade mesma da presença desse sujeito evanescente e subtraído em suas histórias.

Tínhamos como proposta inicial narrar o texto dos livros a partir dos interesses e das "cenas" produzidas pelas crianças no grupo. Tomamos como diretriz de nosso trabalho oferecer-lhes a possibilidade de contato com um elemento forte na cultura: a tradição e a arte de transmitir histórias:

"O contar (e o ouvir) histórias é uma prática que se mantém ao longo da história da humanidade, pela qual os adultos revelam às crianças seus sonhos fantásticos transformados ou adaptados à vida cotidiana.

"As histórias, ao mesmo tempo que resgatam o mundo infantil, inscrevem as crianças no universo cultural, pois indicam - nos seus mais variados enredos - as experiências, memórias e mitos próprios de cada cultura.

"Além disso, possibilitam e atuam na capacidade de sonhar, indicando que a 'realidade' pode ser flexível, que os limites podem ser ultrapassados e que o fantástico, veiculado pelo simbólico, pode tornar o real menos aterrador. Paralelamente à possibilidade de articulação da fantasia, a grande maioria das histórias possui, em sua estrutura, uma moral, indicando que existem normas da cultura - às quais todos estamos, portanto, submetidos - que não podem ser ignoradas".

Nesse período (primeiro semestre de 1996) tínhamos uma configuração de grupo que acreditávamos possibilitar essa condução: 
nem todas as crianças do projeto participavam dessa oficina; era "requisito", para ali estar, alguma tolerância a situações de atendimento consideradas "mais estruturadas", isto é, crianças que agüentassem estar em uma sala apenas com livros e para as quais a "leitura" das cenas funcionasse como um potencializador de novas cenas. Tínhamos também, de maneira geral nesse projeto, a idéia de que a oficina de Contar Histórias seria um passo em direção a um futuro projeto de escolarização para essas crianças - o que, aliás, teve início em 1998, com o intuito de cuidar de sua inserção e acompanhamento escolares.

Em 1997, tivemos algumas mudanças na condução do trabalho, entre elas, a de torná-lo mais abrangente: todas as crianças do projeto participariam de todas as oficinas (até porque o número de crianças que atendíamos não era muito elevado). Nesse novo contexto, tivemos uma configuração de grupo diferente, que se fez sentir logo nos primeiros dias. Nas primeiras semanas desse ano fomos tendo elementos para rever alguns aspectos de nossa proposta, revisão esta que foi sendo efetuada pouco a pouco, até chegarmos à configuração atual.

O que se passou nessa época? A cada oficina saíamos do grupo com restos de papéis picados, pedaços coloridos do que nós, "terapeutas", ao entrarmos na sala, chamáramos livros. Tínhamos diante de nós, em alguns momentos, cenas de absoluta estranheza (Unheimlich), em relação às quais as palavras não funcionavam como mediadoras; pelo contrário, pareciam somar-se à tensão crescente, potencializando-a. Sobre estes momentos, penso na relação entre imagem e agressividade, mencionada por Lacan ao referir-se ao estádio do espelho:

"Existe uma certa dimensão de conflito, que não tem outra solução além de um ou..., ou... É necessário a ele ou tolerar o outro como uma imagem insuportável, que o arrebata de si mesmo, ou quebrá-lo imediatamente, inverter, anular a posição à frente, a fim de conservar aquilo que é, naquele momento, centro e pulsão de seu ser, evocado pela imagem do outro, seja esta especular ou encarnada" (Lacan, 1960-1, p. 340).

$\mathrm{Na}$ composição desse quadro geral, havia as reações peculiares de cada criança, em suas tentativas de se aproximar do novo objeto: Da. dirigia-se aos livros para apagar-lhes as imagens, tentava fazê-lo com saliva ou mesmo rasgando-lhes as páginas (e depois punha-se a mastigar os pedaços de papel); Me. batia-os contra a parede, como se fossem martelos, atento aos sons que emitiam; Pe. lançava-os contra o ventilador, tratando igualmente um livro e uma almofada; Ga., por sua vez, amontoava-os e lia, incessantemente, páginas e páginas, como se não houvesse nelas grandes variações de entonação ou de pontuação. Talvez fosse necessário, neste último caso, encontrar outra palavra, uma vez que a leitura pressupōe o entendimento, coisa que aqui nem sempre parece presente. No caso desta criança, víamos algo muito semelhante ao que Bergès e Balbo (1997) destacam acerca da relação dos não-leitores com ideogramas, pois os lêem de uma 
só vez, abolindo a temporalidade da leitura e, com isso, também impossibilitam a compreensão do texto. No caso de Ga., a questão não estava tanto no contato com este objeto - o livro - que lhe era bem familiar, por aspectos de sua história. A dificuldade maior que se colocava para ele era: como estar em um grupo de crianças que não tinham a mesma familiaridade com livros?; como suportar esperar uma história ser lida, com todas as suas pausas?

O contraste com o agrupamento anterior de crianças e a dificuldade objetiva que se interpôs em nosso trabalho levaram-nos à primeira modificação na maneira de conduzi-lo: os livros não poderiam ser tão frágeis. Só assim permitiriam às crianças um manuseio que lhes possibilitasse mudar o estatuto do contato com este novo objeto. Aí estava, apesar de não o sabermos naquele momento, a primeira pista para o trabalho que precisaríamos desenvolver ao longo desses dois anos. Encapamos cada página dos livros com Contact e os deixamos à disposição das crianças, enquanto líamos as histórias neles contidas. Com isto, pretendíamos viabilizar um caminho que à primeira vista nos parecia impossível.

$\mathrm{O}$ que hoje percebo do que se efetivou com essa iniciativa foi a construção de um campo estável que, ao tornar esse objeto-livro resistente às investidas das crianças, foi promovendo uma certa descontinuidade em relação àquela série infinita de gritos, cacos de livros e batidas que se dissolviam em um único e indiferenciado instante que parecia não ter fim. À medida que sua permanência não trazia os riscos que lhe pareciam inerentes, a situação geral de angústia que acompanhava os momentos em que os livros eram despedaçados (quando as crianças reagiam num crescente desespero, como se nada, a partir de então, pudesse ter a garantia de permanecer existindo) foi se tornando menos freqüente.

Fomos nos dando conta de que esses objetos não eram para essas crianças aquilo que nós lhes dizíamos serem livros; e talvez a idéia de construí-los para eles tal como nós os víamos não fosse o melhor caminho. Essa constatação trouxe-nos um problema em relação à proposta inicial de fornecer narrativas que pudessem servir de cenários, pois o mundo mágico que se torna acessível a partir dos livros e de suas narrativas depende do fato de os considerarmos como tal. Temos então, num primeiro momento, seu reconhecimento enquanto objetos coloridos que contêm traços (que chamamos letras) e grupamentos de cores (que chamamos figuras). A partir da constatação da existência de figuras e letras, temos, num passo adiante, o reconhecimento de que aquele objeto que as contém pode nos servir como "trampolim" para "outra cena", que animará o cenário de nossas identificações. Está implicado então, na relação com a leitura e na apreensão da literatura, algo de pri- 
mordial que nos é requerido no exato momento em que nos debruçamos sobre este objeto:

"No livro, ou antes, na relação com o livro, o importante não é tanto compreendê-lo, mas, de preferência, abrir (e isso graças aos pais) espaços, compartimentos. Quanto mais hipóteses existem em um livro, mais se lê o que existe atrás dos olhos. No livro, passa-se da representação à palavra, da imagem à letra, do imaginário ao simbólico. É uma imbricação total do sentido e do nãosentido que abre portas então, espaços graças aos quais a criança se constitui" (Rassial, 1998, p. 100).

Essa descoberta colocou em questão o que havíamos idealizado quando construímos o projeto do Contar Histórias, e também a direção que pretendíamos lhe dar; mas não o abandonamos arbitrariamente. Neste momento pensamos em tornar mais próximo dessas crianças o contato com o que o livro poderia nos apresentar: a narrativa literária em sua face verossímil; mímesis de um passível de ser vivido, sem os riscos que este imporia. Tomamos aqui por referência o conceito de mímesis elaborado por Walter Benjamin, que não se reduz à imitação, pois trata-se de uma imanência do simbólico. Nesta perspectiva, falar de mímesis não é falar de imitação, mas de figuração simbólica. Faço aqui uma breve pausa para justificar o uso do termo, referenciando-me em um comentário de Gagnebin (1997, pp. 81-106) à concepção benjaminiana deste conceito, no qual a autora se remete aos escritos autobiográficos de Benjamin, em que fica evidenciado o lugar da linguagem como grau último da capacidade mimética humana:

"Pelo movimento do seu corpo inteiro, a criança brinca/representa o nome e assim aprende a falar. (...) Para a criança, as palavras não são signos fixados pela convenção, mas, primeiramente, sons a serem explorados. Benjamin diz que a criança entra nas palavras como entra em cavernas entre as quais ela cria caminhos estranhos. Essa atitude não se deve a uma pretensa ingenuidade infantil'. Pelo contrário, ela testemunha a importância do aspecto material da linguagem que os adultos geralmente esqueceram em proveito do seu aspecto espiritual e conceitual, e que só a linguagem poética ainda lembra.

"O mesmo movimento mimético encontra-se no aprendizado da escrita. Quando a criança começa a escrever, quando ela desenha a letra, ela não só imita o modelo proposto pelo adulto, mas, segundo Benjamin, ao escrever a palavra, ela desenha uma imayem (não uma cópia) da coisa, ela estabelece uma relação figurativa com o objeto" (Gagnebin, 1997, p. 100).

É interessante destacar esta idéia: justamente a linguagem poética permite remeter à experiência primordial de tomar as palavras 
no extremo de sua materialidade, vivenciado-a na sua textura e com o próprio corpo. Meu interesse, com este desvio, é assinalar que Benjamin privilegia o aspecto material da linguagem. Gagnebin evidencia ainda que, mais radicalmente, ele enfatiza a relação figurativa entre a escrita e o real. Curiosamente, ele chega a esta conclusão a partir do estudo da escrita chinesa. Lacan, nos últimos anos de sua obra, período em que começou a estudar as peculiaridades da poesia chinesa, destacou também a relação existente entre a materialidade da letra e o que ele denominara registro do real ${ }^{4}$. Toda esta volta interessa aqui porque se formos pensar em termos de uma direção possível deste trabalho, mesmo que dela não se tenha clareza no exato momento em que ela se tece, este me parece ter sido, gradualmente, o caminho que a oficina foi tomando.

Voltemos então às nossas tentativas de constituir uma oficina: forjamos um "livro" cujas páginas estariam por preencher e nas quais escreveríamos, ao final de cada oficina, uma parte da história que construíamos ao nos encontrarmos semanalmente naquela sala. Tomamos o cuidado de também fazer "reforços" com Contact neste livro, para que pudesse ser manuseado pelas crianças como mais um livro da oficina.

Escrever a "parte do dia" de nossa história passou a compor a rotina dessa oficina, e a narrativa por nós construída a partir dos "feitos" de cada criança, às vezes com a contribuição direta de algumas delas (traços sobre o papel, palavras e frases), passou a funcionar como ponto de ancoragem (e de sustentação para os próprios terapeutas nos dias mais "pesados").

Não pretendo com isso afirmar que a literatura se reduz a uma reprodução autobiográfica; tampouco considerar o que chamo aqui de narrativa (pelo fato de o ser em seu aspecto formal) como correlato de uma narrativa literária. Entretanto, parece-me esta uma metáfora bastante oportuna para pensar a situação de uma oficina que não é qualquer, mas de Contar Histórias.

Mesmo nos dias de maior confusão, no momento de escrever o que fizemos, momento prévio ao encerramento da oficina, algo se produzia nesse ato de escrever o que se passou. Sabíamos bem que o que fazíamos ali era construir, a partir do que nos forneciam as crianças, por seus atos e falas, uma tecedura imaginária, uma narrativa possível nos momentos de desorganização e loucura geral, que não tinha a pretensão de fazer-se suporte de suas maneiras de estar no mundo; mas reconhecíamos a função pacificadora da palavra, sobretudo para nosso funcionamento neurótico.

$\mathrm{E}$, com eles, o que se passava? Da. às vezes se sentava e olhava tranqüila para o livro e quem ali escrevia; Pe. parava de jogar livros pela sala e tentava guardar todos os livros na caixa; Ga., sempre muito preocupado em ordenar as coisas, nesses momentos se aproximava do "narrador" do dia, e lhe dizia: "Escreve aí que..." Num momento seguinte, quando algo dito ou feito por ele seria narrado por escrito, afastava-se do livro, às vezes se escon- 


\section{Dossiê}

dia. Curto-circuito no imaginário, pelo qual tinha que desaparecer no grupo para conseguir estar no livro, figurado, representado por letra ou imagem. Também aqui está em jogo a relação mencionada acima, de agressividade implicada na relação imaginária; mesmo havendo um reconhecimento de si no outro, isto aparece de forma confusa e assume uma dimensão persecutória, uma vez que não é possível ser ao mesmo tempo aquele que olha e o que é olhado.

Nos dois últimos anos do contar histórias que ajudei a construir, pouco a pouco passamos a contar bem menos histórias já escritas e em contrapartida passamos a participar de um novo tipo de "narratividade". Fomos percebendo no contato com essas crianças que a narrativa que podemos oferecer não passa de um pretexto para que produzam suas próprias narrativas. Também aqui utilizo o termo narrativa de maneira singular, no sentido de uma apropriação do que the é apresentado para construir com isto outra coisa, que entretanto the serve como modo de agir sobre o mundo. Tomo aqui emprestada a concepção de narrativa proposta por Michel de Certeau quando se refere ao homem ordinário como aquele que, silenciosamente, e graças às artes de fazer, se apropria do que lhe é imposto pela cultura de massa, fazendo verdadeiras bricolages pelas quais constrói sua narrativa cotidiana. "Enquanto indícios de singularidades - murmúrios poéticos ou trágicos do dia-a-dia -, as maneiras de fazer se introduzem em massa no romance ou na ficção" (Certeau, 1996).

Após três anos de tratamento, Da. chega na sala desse grupo e conta suas histórias, entre risos e ares travessos: "Derramou Yakult no Chilipe", "Fez xixi no chão", "Quebrou o copo do tio", etc. A menina que em 1996, quando chegou à clínica, era descrita, fenomenologicamente, como alguém que apresenta "traços autísticos" muito evidentes (praticamente não falava, e, quando o fazia, o som de sua voz era quase ininteligível; eram raros os contatos de olhar; jogava-se por todos os cantos da sala, freqüentemente trombando com a parede) chega à oficina contando suas "artes", podendo falar ${ }^{5}$; mais ainda, podendo construir com a fala um estar no mundo que antes precisava ser feito sofregamente, com o corpo. Nesse sentido, importa pouco o enredo das histórias que levamos para a sala (que são geralmente as mesmas, que ficam dentro de um baú, onde as crianças possam pegá-las), mas a possibilidade de funcionarem como estofo para outra encenação, que está sempre tentando se efetivar, sempre de forma falhada e evanescente. Pe. ainda joga livros no ventilador; mas não qualquer livro. Curiosamente os seus favoritos são os escritos na oficina (e que contêm também fotos e desenhos ${ }^{6}$ ) e um pequeno livro cujo protagonista tem o nome correspondente às duas primeiras sílabas de seu nome. 
Para além dos enredos, há uma clara eleição de alguns livros por algumas crianças, e uma apropriação muito singular do que contêm. Da. pega sempre o mesmo livro: Cachinhos de Ouro, e refaz a seqüencia das cenas que the interessam. Nesse ato, faz-se designar pelos elementos que nomeia: a menina, o bule, o fogão, o café, quebrou (figura da cadeira do ursinho, quebrada, na historinha, por Cachinhos de Ouro ${ }^{7}$ ). Desta forma, ensaia a construção de uma narrativa, muito distinta, talvez, do enredo desse clássico, mas muito singularmente feita por ela, uma narrativa própria. Ed., o mais novo na oficina, desenha com os livros figuras geométricas, às vezes tridimensionais, tomando o cuidado de escolher os lados dos livros que ficarão visíveis. Nesta "edificação", apostamos, vai fazendo o esforço de construção de uma narrativa, narrativa esta que talvez não saibamos ler, mas cujo estatuto reconhecemos. "O desenrolar da cadeia significante depende daquele que se presta a isso como parceiro, como testemunha, como escrevente, ou ainda como secretário do alienado" (Sauret, 1992, p. 108).

Tomo aqui o termo narrativa como metáfora para pensar o esforço interminável de construção visível na insistência em repetir nessas crianças, pois o que é narrar? Segundo o léxico (Aulete, 1975), narrar é referir, expor, descrever, historiar verbalmente ou por escrito. Eu acrescentaria a estas definições a de construir, pois o que fazemos nós, seres ex-sistentes, se não (re)construir na linguagem o que ficou perdido ao nos tornarmos, forçosamente, falantes? E aqui introduzo a questão de uma alienação primordial da qual nem mesmo um autista escaparia ileso, pois não é absolutamente alheio à marca da linguagem, mesmo que sua reação a ela seja a da recusa.

"Voltemos ao tempo anterior, o da resposta do real ao encontro do significante: o sujeito é essa resposta, escreve Lacan. Só que essa resposta pode ser feita de consentimento ou de recusa. Abordemos, dessa vez, a recusa. Sem dúvida, o sujeito leva a marca dessa recusa que, como tal, é uma marca significante. Poderíamos ilustrá-lo com essa criança que tapa os ouvidos quando o outro the fala, que distingue a fala do barulho, ou esse outro aterrorizado porque todos os objetos se põem a the falar apesar dos seus uivos. Nem um nem outro se encontram no pré-verbal, mas habitam inteiramente a linguagem. Porém, habitam-na mais como objetos - certamente perseguidos pela palavra, o que basta para distingui-los dos objetos" (Sauret, 1998, p. 32).

Pensando na questão da linguagem e no esforço dessas crianças em construir um campo estável que lhes permita alguma ancoragem, o que chamei até aqui de narrativa a ser construída poderia ser nomeado de outra forma, a partir da psicanálise: 
"Apostar que a criança possa instituir seu fantasma $(8<>a)$ e não cair prisioneira do fantasma do $\mathrm{Ou}$ tro. Se o Nome-do-Pai está ausente na estrutura, não se apontará a falta em ser (8), mas a maior 'erosão' possível deste lugar de a e a construção paralela de algum significante suplente que o represente, a construção simbólica de um certo 'estado civil”' (Eidelberg \& Feldstein, p. 88).

Se o que se costuma dizer a respeito da criança psicótica é que ela permanece prisioneira, objeto do fantasma do Outro primordial, não seremos nós, terapeutas, ao tentar fornecer-lhe nossas referências, as de nosso jeito neurótico de funcionar, que lhe daremos a prerrogativa de um lugar outro em relação ao $\mathrm{Ou}$ tro. Não poderíamos fazer isto por ela, mesmo que sinceramente o quiséssemos - e por isto, parece-me, não ceder quanto a psicose implica necessariamente ter que suportar uma certa frustração, a de não ver o tempo construir sólidos monumentos -, os esforços são tamanhos, os efeitos, módicos. Muitas vezes presenciamos $o$ infindável esforço de construção que parece culminar em uma nova ruína; noutras, algo de heroicamente resistente parece ir se constituindo; e isto acontece em casa, na escola, no supermercado, na oficina de contar histórias... desde que haja alguém ali, para testemunhar o ocorrido.

Por fim, ainda fica a questão: $O$ que é um livro para essas crianças? Talvez possamos inferir que para algumas delas seja um amontoado de páginas coloridas com figuras e, quem sabe, letras, ou uma textura que permita emitir um som particu- lar; ou um conjunto de formas que permitam fabricar uma estrutura tridimensional... No meu entender, isto não é pouco. Nossa função ao acompanhá-las nesse contato talvez seja exatamente estar ali com a simples aposta; quase como testemunhas de que o ato pelo qual se aproximam destes objetos inscreve suas tentativas de construir um saber que possa descompletar o saber absoluto do Outro, e com isso furtar-se à sentença de congelamento neste lugar de objeto do seu gozo. E isto também não é pouco.

\section{REFERÊNCIAS BIBLIOGRÁFICAS}

Aulete, C. (1975). Dicionário da língua portuguesa, Vol. 4. Rio de Janeiro, RJ: Delta, 5 "ed.

Bergès, J. \& Balbo, G. (1997). A criança e a psicanálise. Porto Alegre, RS: Artes Médicas.

Certeau, M. de (1996). A invenção do cotidiano. Petrópolis, RJ: Vozes.

Eidelberg \& Feldstein. EI niño como objeto del fantasma materno: soborno y sacrificio.

Gagnebin, J. M. (1997). Sete aulas sobre linguagem, memória e história. Rio de Janeiro, RJ: Imago.

Lacan, J. (1960-1). O seminário, Livro VIII, A transferência. Rio de Janeiro, RJ: Jorge Zahar, 1992.

Rassial, A. (1998). O livro antes da leitura (L. S. Prado, trad.). In Dos contos em cantos. Salvador, BA: Ágalma.

Sauret, M.-J. (1992). De l'infantile à la structure. Les Séries de la Découverte Freudienne. Toulouse: Presses Universitaires du Mirail.

(1998). O infantil e a estrutura. São Paulo, SP: EBP. 
1 Trecho traduzido por Jeanne Marie Gagnebin (1997).

2 Trecho retirado do projeto original da oficina, elaborado em 1996.

3 Assim são chamadas as pessoas que conduzem as oficinas na PUC.

4 Faço aqui uma aproximação meio tosca, pois o conceito de real em Lacan é bastante específico e seria necessário um acurado estudo (ao qual este trabalho nāo se propõe), que fizesse as devidas aparas nas semelhanças e diferenças deste conceito para ambos os autores.

5 E isto certamente porque teve, além das oficinas, no atendimento familiar, um espaço privilegiado para ir construindo, pouco a pouco, este caminho.

6 A cada ano há um novo livro da oficina a ser escrito; o de 97 , primeiro da série, é um dos favoritos das crianças, que - folheiam e vão relembrando episódios, muitas vezes não com palavras, mas repetindo-os.

7 Aspecto que tem muito a ver com a peculiaridade do lugar que foi possivel construir para ela em sua familia.

Recebido em agosto/2000. 